\title{
Association between objectively measured physical activity and body mass index with low back pain: a large-scale cross-sectional study of Japanese men
}

Yuko Hashimoto ${ }^{1}$, Ko Matsudaira ${ }^{2}$, Susumu S. Sawada ${ }^{3 *}$, Yuko Gando ${ }^{3}$, Ryoko Kawakami ${ }^{4}$, Robert A. Sloan ${ }^{5}$, Chihiro Kinugawa ${ }^{6}$, Takashi Okamoto $^{6}$, Koji Tsukamoto $^{6}$, Motohiko Miyachi ${ }^{3}$ and Hisashi Naito ${ }^{1}$

\begin{abstract}
Background: The relationship between the combination of physical activity (PA) and body mass index (BMI) with low back pain (LBP) is unclear. The present study offers a cross-sectional assessment of how combinations of PA and BMI are related to LBP in Japanese men.

Methods: Participants were 4022 Japanese men (mean age $=47$ ) who underwent regular clinical examinations. PA was measured using a uniaxial accelerometer and divided into tertiles ( $\left.P A_{h i g h}, P A_{\text {middle, }}, P A_{\text {loww }}\right)$. A self-administered questionnaire was used to report on persistent LBP experience, drinking and smoking habits, and any existing lifestyle diseases. After covariance adjustment, a logistic regression model was used to assess how combinations of PA and BMI are related to persistent LBP.

Results: 428 of the participants had persistent LBP. A clear negative dose-response relationship was found between PA levels and persistent LBP (P for linearity $=0.012)$. Regarding $B M I$, odd ratios were shown to be higher in the overweight/obese category (BMI $\geq 25 \mathrm{~kg} / \mathrm{m}^{2}$ ) than for the normal weight category $\left(\mathrm{BMl}<25 \mathrm{~kg} / \mathrm{m}^{2}\right)$. When the $\mathrm{PA}_{\text {high }}$ was taken as the reference in the normal weight category, odds ratios for $\mathrm{PA}_{\text {low }}$ and $\mathrm{PA}_{\text {middle }}$ in the normal weight category were shown to be high. Moreover, in the overweight/obese category, odd ratios for every fitness level were also high as for the normal weight category.

Conclusion: The present study showed that both PA and BMI are related to persistent LBP. Also, the prevalence of persistent LBP became higher when $\mathrm{PA}_{\text {low }}$ and high $\mathrm{BMI}$ are combined rather than the group of $\mathrm{PA}_{\text {high }}$ and low BMl combination.
\end{abstract}

Keywords: Accelerometry, Epidemiology, Physical activity, Low back pain, Body mass index

\section{Background}

Low back pain (LBP) ranks the highest in symptom that affect years lived with disability and currently is a health issue worldwide [1]. In national health and nutrition surveys in Japan as well, LBP is ranked highest for men among those reporting subjective symptoms for disease or injury [2]. LBP affects not only health but also

\footnotetext{
* Correspondence: yususumi@gmail.com

${ }^{3}$ Department of Physical Activity Research, National Institutes of Biomedical Innovation, Health and Nutrition, 1-23-1 Toyama, Shinjuku-ku, Tokyo 162-8636, Japan

Full list of author information is available at the end of the article
}

productivity and leads to loss of labor and decline in workforce and productivity, thus causing economic losses to society [3].

The lack of physical activity (PA) [4] and body mass index (BMI) [5] have been reported to be related to a variety of diseases, and many reports exist on the relationship between PA and LBP [6-12] as well as the relationship between BMI and LBP [11-15]. However, study results for both relationships are diverse, and the relationship for each with LBP is not quite clear. The reason behind the variation in study results is perhaps due to the differences in measuring methods for the various 
indices or differences in the studied populations. Most studies have used self-report questionnaires to measure PA but some have reported the challenges of the subjective method [16, 17]. Also, only few small-scale studies have used objectively measured PA via accelerometer [18-20]. Furthermore, no studies observed Asian populations, and there are no investigations regarding the combinations of PA and BMI related to LBP.

There are some related plausible mechanisms regarding the relationships between PA and obesity with LBP. Both PA and obesity yield some different endogenous substances. From previous studies, PA seems to contribute mood change and pain reduction, [21, 22] and obesity, which yields enlarged fat cell disrupt the balance of the secretion system and are possibly related to pain [23].

Based on the relationships and mechanisms of PA, obesity, and pain above, we set up a hypothesis that there is a relationship between the combination of low PA and high BMI with high prevalence of LBP. Therefore, we examined how combinations of PA and BMI are related with LBP in over 4000 Japanese men using an accelerometer to objectively measure the amount of physical activity.

\section{Methods}

\section{Participants}

Participants were 9167 workers of a single company in metropolitan Tokyo and the ratio of blue-collar to white-collar workers was approximately 6:4. The participants underwent a clinical examination under the Industrial Safety and Health Act in Japan between September 2009 and August 2010. Out of these 9167 participants, the focus was on 6400 participants who measured PA with an accelerometer. Then, 938 who measured PA using the accelerometer for less than seven days were excluded. 27 participants were excluded because of double measurement of physical activity, then 51 participants were excluded due to lack of clinical examination data. Participants who did not fully complete the questionnaire relating to their PA measurement $(n=320)$ and LBP $(n=376)$ were excluded. Moreover, since the number of female's data was low $(n=666)$, we excluded them from the analysis. Finally, the examined population for analysis in this research consisted of 4022 men (Figure 1).

In our observational study, the participants gave written informed consent for research use and publication of his/her data before commencement of the study and the clinical examinations were done under the Industrial Safety and Health Act and related laws in Japan. This study was approved by the ethics committee of the $\mathrm{Na}$ tional Institutes of Health and Nutrition (290-01).

\section{Clinical examination}

At the clinical examination, height $(\mathrm{m})$ and body weight $(\mathrm{kg})$ were measured in light clothes without shoes, and all participant's height and weight were recorded by the same scale with the same condition. BMI was obtained from height and weight measurements (weight divided by height squared) by questionnaire, and are divided into two categories using the WHO BMI standard, that is normal weight $(<25 \mathrm{~kg} / \mathrm{m} 2)$ and overweight/obese ( $\geq$ $25 \mathrm{~kg} / \mathrm{m} 2$ ). Participants were asked about drinking and smoking habits, and if they were receiving treatment at the time for hypertension, dyslipidemia, or diabetes.

\section{Measurement of physical activity}

PA was measured using a Lifecorder PLUS (Suzuken Co., Ltd), a uniaxial accelerometer, and it determines the number of steps and the physical activity level (1 to 9)

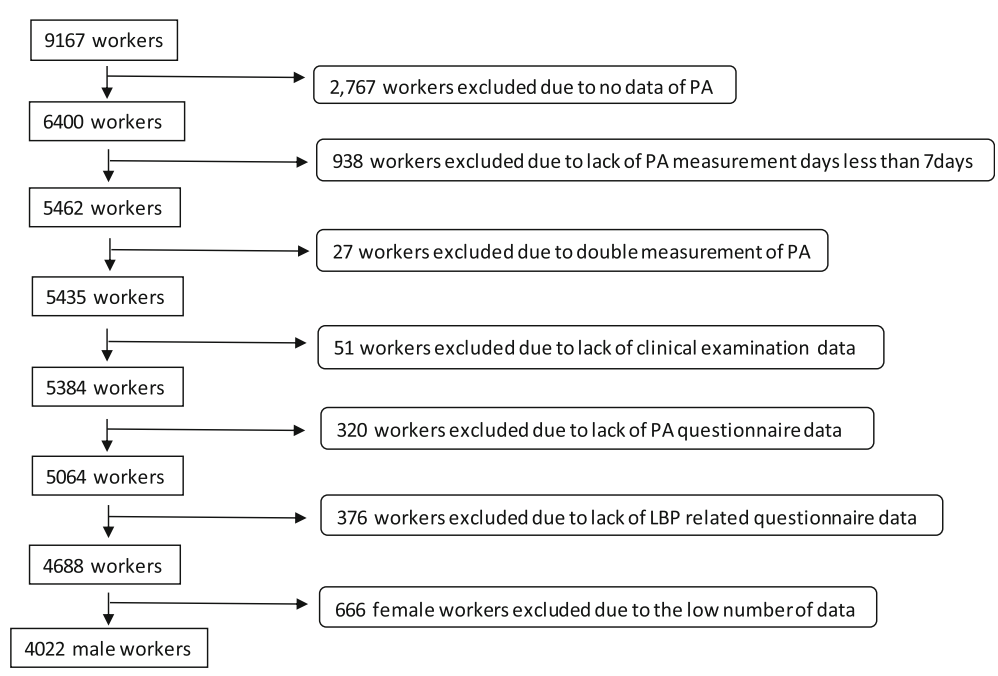

Fig. 1 Flowchart of the sample selection for the present study 
per day. Suitability and reliability of the accelerometer used in the present study have been confirmed in previous studies [24, 25]. Accelerometers were distributed to participants due for a clinical examination two months prior. Also, from the participants who agreed to participate in the study, median values for each participant were collected concerning moderate-vigorous PA $(\geq 3$ METs) times (min/day) as indicators of PA [26]. In this study, based on Kumahara's criteria [24], the intensities were defined as 1 to 3,4 to 6 , and 7 to 9 as light $(<3$ METS), moderate (3-6METS), and vigorous ( $>6$ METS) intensity of physical activity and PA was considered as $\geq 3$ METs, which is more than moderate-vigorous PA. We did not consider bout length. Participants who consented to take part in the study were asked to wear the accelerometer for two weeks or more and $12 \mathrm{~h}$ or more per day [27]. The criteria for data to be selected for the use were set at a minimum of seven days where the acceleration was detected for $10 \mathrm{~h}$ or more per day [28].

\section{Ascertainment of low back pain}

Experience of LBP was examined using a selfadministered questionnaire at the time of the clinical examination. Under the question concerning objective symptoms, the following three responses were provided as options for LBP: None, Sometimes (Intermittent), and All the time (Persistent). Based on previous studies, persistent LBP was considered as continuous pain $[29,30]$. Therefore, we defined participants who responded "All the time" on the self-administered questionnaire as people who have persistent LBP, and excluded people who answered sometimes (Intermittent).

\section{Statistical analysis}

First, we compared characteristics for participants with persistent LBP and those without. PA for all participants were divided into three categories $\left(\mathrm{PA}_{\text {high }}, \mathrm{PA}_{\text {middle, }}\right.$, $\left.\mathrm{PA}_{\text {low }}\right)$ based on tertiles. Each classification was $\leqq 49.1 \mathrm{~min} /$ day (high), 33.9-49.1 minuets/day (middle), and $\geqq 33.9 \mathrm{~min} /$ day (low) respectively. By combining two BMI categories (Normal weight, Overweight/obese) and three PA level categories, a total of six categories were established (Normal weight - $\mathrm{PA}_{\text {high }}$, Normal weight $-\mathrm{PA}_{\text {middle }}$, Normal weight $-\mathrm{PA}_{\text {low }}$, Overweight/ obese - $\mathrm{PA}_{\text {high }}$, Overweight/obese - $\mathrm{PA}_{\text {middle, Over- }}$ weight/obese - $\mathrm{PA}_{\text {low }}$ ), and the characteristics of these six categories were compared. Next, to study the relationship between persistent LBP with PA and BMI, respectively, logistic regression analysis was performed with the presence of persistent LBP as the dependent variable and PA (three categories) or BMI (two categories) as the independent variables. The odds ratios (ORs) and the 95\% confidence intervals (CIs) adjusted for age were calculated. Moreover, the ORs adjusted for hypertension (yes, no), dyslipidemia (yes, no), diabetes (yes, no), drinking habits (drinker, nondrinker), and smoking habits (nonsmoker, smoker, former smoker) were obtained. As a final adjustment, ORs were obtained for PA with added BMI $\left(\mathrm{kg} / \mathrm{m}^{2}\right)$ and BMI with added PA (minutes/day). To assess the relationship between the six categories combining $\mathrm{PA}$ and $\mathrm{BMI}$ and persistent LBP, logistic regression analysis was performed with persistent LBP as a dependent variable and the six categories with combinations of PA and BMI as independent variables. Then $95 \%$ CIs and ORs adjusted for confounding factors were calculated. Additionally, to confirm whether or not there was any effect modification of PA or BMI, the existence of interaction was confirmed by inserting product terms PA (minutes/day) and BMI $(\mathrm{kg} /$ $\mathrm{m}^{2}$ ) into the model. All statistical analyses were performed using SPSS Statistics version 21(SPSS Japan Inc., Tokyo, Japan), and a two-tailed $P$ value less than .05 was considered to be statistically significant.

\section{Results}

Out of the 4022 participants, 428 had persistent LBP. Participant characteristics for those with and without persistent LBP are shown in Table 1. Age and BMI in participants with persistent LBP were high, whereas PA was low. Smoking and drinking rates and overall ratios of lifestyle disease tended to be high in participants with persistent LBP.

Participant characteristics for the six categories with PA/BMI combinations are shown in Table 2. This shows that in the two obesity status categories, the number of people in the normal weight category is twice the number in the overweight/obese category. Moreover, age tends to be higher in the overweight/obese category than in the normal weight category across the $\mathrm{PA}_{\text {low }}, \mathrm{PA}_{\text {middle, }}$ and $\mathrm{PA}_{\text {high. }}$. The absolute risk of persistent LBP was the highest when overweight/obese and $\mathrm{PA}_{\text {low }}$ are combined. Regardless of normal weight or overweight/obese, the absolute risk of persistent LBP increased with the lowering of physical activity levels. No constant trend was found for drinking rates, but smoking rates were highest in the category with $\mathrm{PA}_{\text {low }}$, both in the overweight/obese and normal weight categories. High values were shown for hypertension, dyslipidemia, and diabetes in the overweight/obese category.

The ORs for persistent LBP by PA and by obesity status are shown in Table 3. $\mathrm{PA}_{\text {low }}$ showed higher ORs than $\mathrm{PA}_{\text {high }}$, and a clear negative dose-response relationship was found between PA and having persistent LBP (P for linearity $=0.012$ ). For $\mathrm{BMI}$, the high category (overweight/obese; $\mathrm{BMI} \geq 25 \mathrm{~kg} / \mathrm{m}^{2}$ ) showed higher ORs than the low category (normal weight; $\mathrm{BMI}<25 \mathrm{~kg} / \mathrm{m}^{2}$ ). No significant interaction was observed between $\mathrm{PA}$ and obesity status ( $\mathrm{P}$ for interaction $=0.477$ ). 
Table 1 Characteristics of Japanese Men According to Persistent LBP

\begin{tabular}{|c|c|c|c|}
\hline Characteristics & Total & With Persistent LBP & Without Persistent LBP \\
\hline N & 4022 & 428 & 3594 \\
\hline Age, years & $47(10)$ & $49(9)$ & $47(10)$ \\
\hline $\mathrm{BMI}, \mathrm{kg} / \mathrm{m}^{2}$ & $23.8(3.2)$ & $24.2(3.5)$ & $23.8(3.1)$ \\
\hline Physical activity, minutes/day & $42.7(18.5)$ & $40.5(17.6)$ & $43.0(18.5)$ \\
\hline \multicolumn{4}{|l|}{ Drinking, \% } \\
\hline Nondrinker & 14.5 & 14.0 & 14.6 \\
\hline Drinker & 85.5 & 86.0 & 85.4 \\
\hline \multicolumn{4}{|l|}{ Smoking, \% } \\
\hline Nonsmoker & 35.9 & 30.8 & 36.5 \\
\hline Smoker & 36.6 & 38.1 & 36.4 \\
\hline Former smoker & 27.5 & 31.1 & 27.0 \\
\hline \multicolumn{4}{|l|}{ Lifestyle-related diseases, \% } \\
\hline Hypertension & 17.4 & 20.3 & 17.0 \\
\hline Dyslipidemia & 8.9 & 9.8 & 8.8 \\
\hline Diabetes & 5.4 & 7.7 & 5.1 \\
\hline
\end{tabular}

Data are means (SD) or \%

LBP Low back pain, $B M I$ Body mass index, SD Standard deviation

The ORs for persistent LBP in the six categories with PA and obesity status combinations are shown in Table 4. When taking $\mathrm{PA}_{\text {high }}$ at normal weight $\left(\mathrm{BMI}<25 \mathrm{~kg} / \mathrm{m}^{2}\right)$ as the standard, $\mathrm{PA}_{\text {middle }}$ and $\mathrm{PA}_{\text {low }}$ ORs showed to be high for normal weight. Furthermore, similarly high ORs as for normal weight are shown for $\mathrm{PA}_{\text {high }}, \mathrm{PA}_{\text {middle, }}$ and $\mathrm{PA}_{\text {low }}$ for overweight/obese $\left(\mathrm{BMI} \geq 25 \mathrm{~kg} / \mathrm{m}^{2}\right)$, and the $\mathrm{PA}_{\text {low }}$ OR was the highest at 1.75 (95\% CI, 1.22-2.53).

Additionally, the results of the combined "None/ Sometime (intermittently)" and "All the time (Persistent)" group of LBP are provided in an additional file as a sensitivity analysis (Additional file 1).

\section{Discussion}

This study shows a cross-sectional assessment of the relationship between objectively measured PA and BMI, with persistent LBP in 4022 Japanese men. A negative dose-response relationship was found between PA and persistent LBP, and a positive relationship was found between BMI and persistent LBP. Regardless of normal weight or overweight/obese, the absolute risk of persistent LBP slightly increased with the lowering of physical activity level (from 7.9\% to $13.8 \%$ ) and no support was obtained for effect modification.

Table 2 Characteristics of participants according to PA levels and BMI

\begin{tabular}{|c|c|c|c|c|c|c|}
\hline \multirow{2}{*}{$\frac{\text { Obesity status }}{\text { Physical activity levels }}$} & \multicolumn{3}{|c|}{ Normal weight $(\mathrm{BMI}<25)$} & \multicolumn{3}{|c|}{ Overweight/Obese (BMI $\geq 25$ ) } \\
\hline & High & Middle & Low & High & Middle & Low \\
\hline N & 935 & 927 & 906 & 402 & 416 & 436 \\
\hline Persistent low back pain (\%) & 7.9 & 11.4 & 10.3 & 10.2 & 13.0 & 13.8 \\
\hline Age, years & $47(10)$ & $46(10)$ & $47(10)$ & $49(9)$ & $47(9)$ & $49(9)$ \\
\hline $\mathrm{BMI}, \mathrm{kg} / \mathrm{m}^{2}$ & $22.1(1.8)$ & $22.3(1.7)$ & $22.2(1.8)$ & $27.4(2.3)$ & $27.2(2.2)$ & $27.7(3.0)$ \\
\hline Physical activity, minutes/day & $62.9(14.0)$ & $41.4(4.3)$ & $24.2(7.3)$ & $62.6(13.3)$ & $41.5(4.5)$ & $23.4(7.4)$ \\
\hline Drinkers (\%) & 85.5 & 84.6 & 86.1 & 86.3 & 88.2 & 82.8 \\
\hline Smokers (\%) & 32.7 & 34.8 & 39.4 & 33.6 & 39.2 & 43.1 \\
\hline Hypertension (\%) & 12.9 & 9.0 & 15.8 & 26.6 & 30.3 & 27.1 \\
\hline Dyslipidemia (\%) & 6.6 & 5.0 & 7.5 & 14.2 & 15.4 & 14.2 \\
\hline Diabetes (\%) & 3.5 & 3.9 & 3.0 & 11.2 & 8.2 & 9.6 \\
\hline
\end{tabular}

Data are means (SD) or \%

$B M I$ Body mass index, SD Standard deviation 
Table 3 Multivariable-adjusted odds ratio for persistent LBP by PA levels and BMI

\begin{tabular}{|c|c|c|c|c|c|c|}
\hline & $N$ & $\begin{array}{l}\text { With Persistent } \\
\text { LBP }\end{array}$ & $\begin{array}{l}\text { Persistent LBP per } 100 \\
\text { men }\end{array}$ & $\begin{array}{l}\text { Age-adjusted OR (95\% } \\
\text { Cl) }\end{array}$ & $\begin{array}{l}\text { Multivariable }{ }^{a} \text { OR }(95 \% \\
\text { Cl) }\end{array}$ & $\begin{array}{l}\text { Multivariableb OR (95\% } \\
\mathrm{Cl})\end{array}$ \\
\hline \multicolumn{7}{|c|}{ Physical activity levels } \\
\hline High & 1337 & 115 & 8.6 & 1.00 (reference) & 1.00 (reference) & 1.00 (reference) \\
\hline Middle & 1343 & 160 & 11.9 & $1.46(1.14-1.89)$ & $1.46(1.13-1.88)$ & $1.46(1.13-1.88)$ \\
\hline Low & 1342 & 153 & 11.4 & 1.37 (1.06-1.76) & $1.36(1.05-1.76)$ & 1.35 (1.04-1.74) \\
\hline $\begin{array}{l}\text { P for } \\
\text { linearity }\end{array}$ & & & & 0.009 & 0.009 & 0.012 \\
\hline \multicolumn{7}{|c|}{ Obesity status } \\
\hline $\mathrm{BMI}<25$ & 2768 & 273 & 9.9 & 1.00 (reference) & 1.00 (reference) & 1.00 (reference) \\
\hline $\mathrm{BMI} \geq 25$ & 1254 & 155 & 12.4 & $1.26(1.02-1.55)$ & $1.22(0.99-1.52)$ & $1.22(0.98-1.51)$ \\
\hline
\end{tabular}

LBP Low back pain, BMI Body mass index, OR Odds ratio, Cl Confidence interval

${ }^{a}$ Adjusted for age (years), hypertension (yes, no), dyslipidemia (yes, no), diabetes (yes, no), drinking (nondrinker, drinker), and smoking (nonsmoker, smoker, former smoker)

${ }^{b}$ Further adjusted for body mass index $\left(\mathrm{kg} / \mathrm{m}^{2}\right.$ ) for physical activity categories or physical activity (minutes/day) for obesity status

In research that reports similar results to this study regarding the relationship between PA and LBP, Ryan CG et al. report that patients with chronic LBP perform fewer steps per day than patients with non-chronic LBP and also have shorter walking periods [18]. Lin et al. also report in a systematic review that patients with chronic LBP with a high level of disability tend to have low PA [6]. Moreover, some studies report that participants that have moderate levels of PA have few instances of chronic LBP patients $[8,9]$. This study demonstrates similar results to these studies. On the other hand, Kamada et al. [10] did not find a clear relationship between PA and LBP. It is believed that since this study evaluated PA using a questionnaire, PA was not ascertained accurately. This study uses actual accelerometer measurements of $\mathrm{PA}$, and we believe that the relationship between PA and LBP is assessed accurately.

With regard to the relationship between BMI and LBP, the HUNT study [14] reports, as the present study, a significant positive relationship between BMI and persistent LBP. In the HUNT study, which looks at Western populations, BMI distribution differs greatly from the male participants in our study. When male participants are divided into two categories using the WHO BMI standard, that is normal weight $\left(<25 \mathrm{~kg} / \mathrm{m}^{2}\right)$ and overweight/ obese $\left(\geq 25 \mathrm{~kg} / \mathrm{m}^{2}\right)$, the proportion for participants of the HUNT study were $34 \%$ and $71 \%$, respectively, whereas in this study, they significantly differ at $69 \%$ and $31 \%$. However, since a positive relationship between BMI and LBP is observed for both of them, regardless of the difference with Western countries and Asia, it is believed that a relative tendency to obesity, rather than absolute BMI values, is a risk factor for having persistent LBP.

First, the following are two plausible mechanisms to explain the study's result of the relationship between PA and LBP: 1) PA is low because people are suffering from persistent LBP, and 2) people have persistent LBP caused by the fact that PA is low. Concerning the first, one factor that can be offered is fear-avoidance beliefs (FAB), when patients excessively avoid activities due to anxiety and fear towards pain. Wertli et al. says that the reduction of FAB in patients may avoid delayed recovery and chronicity [31]. For the reason that patients experience persistent LBP because of low PA, the second point above, it can be considered to be pain relief due to PA.

Table 4 Multivariable-adjusted odds ratio for persistent LBP according to combined PA levels and BMI at baseline

\begin{tabular}{|c|c|c|c|c|c|c|}
\hline Obesity status & $\begin{array}{l}\text { Physical activity } \\
\text { levels }\end{array}$ & $N$ & $\begin{array}{l}\text { With Persistent } \\
\text { LBP }\end{array}$ & $\begin{array}{l}\text { Persistent LBP per } 100 \\
\text { men }\end{array}$ & $\begin{array}{l}\text { Age-adjusted OR (95\% } \\
\text { Cl) }\end{array}$ & $\begin{array}{l}\text { Multivariable }{ }^{a} \text { OR (95\% } \\
\text { Cl) }\end{array}$ \\
\hline \multirow[t]{3}{*}{ Normal weight $(\mathrm{BMI}<25)$} & High & 935 & 74 & 7.9 & 1.00 (reference) & 1.00 (reference) \\
\hline & Middle & 927 & 106 & 11.4 & $1.53(1.12-2.09)$ & $1.52(1.11-2.08)$ \\
\hline & Low & 906 & 93 & 10.3 & $1.33(0.97-1.83)$ & $1.33(0.96-1.83)$ \\
\hline \multirow{3}{*}{$\begin{array}{l}\text { Overweight/obese (BMI } \geq \\
\text { 25) }\end{array}$} & High & 402 & 41 & 10.2 & $1.28(0.86-1.92)$ & $1.25(0.83-1.87)$ \\
\hline & Middle & 416 & 54 & 13.0 & $1.72(1.19-2.50)$ & $1.68(1.15-2.44)$ \\
\hline & Low & 436 & 60 & 13.8 & $1.80(1.26-2.59)$ & $1.75(1.22-2.53)$ \\
\hline
\end{tabular}

LBP Low back pain, BMI Body mass index, OR Odds ratio, $C I$ Confidence interval

${ }^{a}$ Adjusted for age (years), hypertension (yes, no), dyslipidemia (yes, no), diabetes (yes, no), drinking (nondrinker, drinker), and smoking (nonsmoker, smoker, former smoker) 
Relevant endogenous substances include endogenous cannabinoids and opioids, which are reported to contribute to post-exercise mood changes and affect the central nervous system mechanisms of pain modulation [21, 22]. Reports also exist that light to moderate spare-time PA is effective in preventing LBP [32]. Furthermore, another report states that PA on its own or in combination with education is effective in preventing LBP [33].

Next, the following two are plausible mechanisms to explain the study's result of the relationship between obesity and persistent LBP: 1) a biomechanics perspective and 2) a relationship with an endogenous substance. The first is the biomechanics perspective of stress on the spine (intervertebral discs) caused by enlarged stomach due to obesity, as seen in excessive thoracic kyphosis or lumbar lordosis caused by increased downward center of gravity in obese people [34]. Flexing the upper body forward further increases the gravitational force and increases stress on the intervertebral discs, which forms the main reason for the increased power that is required from the back muscle groups. Regarding the relationship with endogenous substances, there is a possible relationship between pain and proinflammatory cytokines, which are induced by adipokines secreted by enlarged fat cells. Typical of these are tumor necrosis factor-alpha (TNF- $\alpha$ ) and interleukin-6 (IL-6), and blood levels of IL6 are thought to be elevated in obese patients [23]. Accordingly, secretion defects for endogenous substances such as adipokines and proinflammatory cytokines in enlarged fat cells disrupt the balance of the secretion system and are possibly related to pain. Additionally, there is myokine, an endogenous substance that promotes the decomposition of fat which is secreted by exercised muscles. Myokines extend to several tens of types, and their action in controlling systemic and slight chronic inflammation has been confirmed [35].

Based on the four mechanisms described above, fat burning and pain relief through PA is believed to be a few of the mechanisms of PA preventing LBP. It is possible that this mechanism explains the relationship of a higher LBP ratio in $\mathrm{PA}_{\text {low }}$ that was shown in this study. Moreover, there is also the possibility that, regardless of the standard of obesity, maintaining current weight and avoiding further weight gain can prevent persistent LBP. Due to the cross-sectional study design, any causal relationship cannot be mentioned, but it suggests that if people have persistent LBP caused by low PA and being obese, respectively, encouraging people to engage in weight control including physical activity such as walking as part of daily life will not only help prevent lifestyle diseases, metabolic syndrome, cardiovascular diseases, and mental health problems in Japanese men but will also contribute to the prevention of LBP.
The present study has some limitations. First, subjects were employees of a single company and it is based only on data for men from an industry with a limited number of people, so there are limits to its generalizability. Moreover, the question of LBP was very simple and definition of persistent LBP does not consider degrees of chronicity, disability, specific body area, or symptoms, so reliability and validity of these data have not been confirmed. Also, accelerometer was performed for more than 2 weeks, the symptomatology could possibly have disappeared. However, since we did not include participants who answered 'sometimes (intermittent)' for the analysis, we consider the participants we analyzed have a high possibility of presenting persistent LBP. On the other hand, our strength is that measurements were taken using an accelerometer, resulting in objective indices for PA, and additionally that the study was on an unprecedented large scale. To determine if PA and obesity status contribute to the prevention of persistent LBP, we hope to conduct a longitudinal study of the relationship between amount of PA, obesity status, and LBP in the future. Furthermore, we hope to conduct a study that includes various populations including women and increases generalizability and provides a more accurate grasp of LBP experience.

\section{Conclusion}

This study shows that both moderate-vigorous PA $(\geq 3$ METs) and BMI are related to having persistent LBP. Also, the prevalence of persistent LBP became higher when $\mathrm{PA}_{\text {low }}$ and high $\mathrm{BMI}$ are combined rather than the group of $\mathrm{PA}_{\text {high }}$ and low $\mathrm{BMI}$ combination.

\section{Additional file}

Additional file $\mathbf{1}$ Table S1-B: Sensitivity Analysis, Table S2-B: Sensitivity Analysis. Sensitivity analysis of the results of the combined "None/ Sometime (intermittently)" and "All the time (Persistent)" group of LBP compared to the "All the time (Persistent)" group of LBP. (DOCX $24 \mathrm{~kb}$ )

\section{Abbreviations}

BMI: Body mass index; Cl: Confidence interval; FAB: Fear-avoidance beliefs; IL6: Interleukin-6; LBP: Low back pain; OR: Odds ratio; PA: Physical activity; TNFa: Tumor necrosis factor-alpha; WHO: World Health Organization

\section{Acknowledgements \\ The authors thank the study participants and the physicians and medical staff of Tokyo Gas Company for their cooperation with this study. We also owe much to Mr. Benjamin Howe for his valuable advice.}

\section{Funding}

This work was supported in part by a collaborative research grant from the Juntendo University Graduate School of Health and Sports Science and Institute of Health and Sports Science \& Medicine (1412404, YH), Grant-in-Aid for Scientific Research (15 K01677, SSS), and a grant from the Ministry of Health, Labour and Welfare of Japan (29061001, MM). 


\section{Availability of data and materials}

The datasets used and/or analyzed during the current study are available from the corresponding author on reasonable request.

\section{Authors' contributions}

Study concept and design: YH, SSS, RK. Acquisition of data: SSS, CK, TO, KT. Analysis and interpretation of data: YH, KM, SSS, YG, RK, RAS, MM, HN. Preparation of initial manuscript: YH, KM, SSS, YG, RK, HN. All authors have critically reviewed and approved the final manuscript.

\section{Ethics approval and consent to participate}

In our study, the participants gave written informed consent before beginning of the study. This study was approved by the Research Ethics Committee of the National Institutes of Biomedical Innovation, Health and Nutrition (290-01)

\section{Consent for publication}

Not applicable.

\section{Competing interests}

The authors declare that they have no competing interests.

\section{Publisher's Note}

Springer Nature remains neutral with regard to jurisdictional claims in published maps and institutional affiliations.

\section{Author details}

${ }^{1}$ Faculty of Health and Sports Science, Graduate School of Juntendo University, 1-1 Hirakagakuendai, Inzai, Chiba 270-1695, Japan. ${ }^{2}$ Department of Medical Research and Management for Musculoskeletal pain, 22nd Century Medical and Research Center, Faculty of Medicine, The University of Tokyo Hospital, 7-3-1, Hongo, Bunkyo-ku, Tokyo 113-8655, Japan. ${ }^{3}$ Department of Physical Activity Research, National Institutes of Biomedical Innovation, Health and Nutrition, 1-23-1 Toyama, Shinjuku-ku, Tokyo 162-8636, Japan. ${ }^{4}$ Faculty of Sport Sciences, Waseda University, 2-579-15 Mikajima, Tokorozawa city, Saitama 359-1192, Japan. ${ }^{5}$ Department of Psychosomatic Internal Medicine, Graduate Medical and Dental School, Kagoshima University, 8-35-1 Sakuragaoka, Kagoshima city, Kagoshima 890-8544, Japan. ${ }^{6}$ Tokyo Gas Co, Ltd., 1-5-20 Kaigan, Minato-ku, Tokyo 105-8527, Japan.

\section{Received: 6 October 2017 Accepted: 2 March 2018}

\section{Published online: 09 March 2018}

\section{References}

1. Global Burden of Disease Study C. Global, regional, and national incidence, prevalence, and years lived with disability for 301 acute and chronic diseases and injuries in 188 countries, 1990-2013: a systematic analysis for the global burden of disease study 2013. Lancet. 2015;386:743-800

2. Ministry of Health Labour and Welfare. Handbook of health and welfare statistics 2016 contents. Part 2 Health Chapter 2 Healthcare, Table 2-53 Total number of symptoms in persons with subjective symptoms by sex, age group and type of symptom 2013 http://www.mhlw.go.jp/english/ database/db-hh/2-2.html Accessed 17. 08. 16.

3. Takura T, Ushida T, Kanchiku T, Ebata N, Fujii K, DiBonaventura M, et al. The societal burden of chronic pain in Japan: an internet survey. J Orthop Sci. 2015;20:750-60.

4. Wen CP, Wai JP, Tsai MK, Yang YC, Cheng TY, Lee MC, et al. Minimum amount of physical activity for reduced mortality and extended life expectancy: a prospective cohort study. Lancet. 2011;378:1244-53.

5. Haslam DW, James WP. Obesity. Lancet. 2005;366:1197-209.

6. Lin CW, McAuley JH, Macedo L, Barnett DC, Smeets RJ, Verbunt JA. Relationship between physical activity and disability in low back pain: a systematic review and meta-analysis. Pain. 2011;152:607-13.

7. Griffin DW, Harmon DC, Kennedy NM. Do patients with chronic low back pain have an altered level and/or pattern of physical activity compared to healthy individuals? A systematic review of the literature. Physiotherapy. 2012;98:13-23.

8. Heneweer $H$, Vanhees L, Picavet HS. Physical activity and low back pain: a U-shaped relation? Pain. 2009;143:21-5.
9. Kayihan G. Relationship between daily physical activity level and low back pain in young, female desk-job workers. Int J Occup Med Environ Health. 2014;27:863-70.

10. Kamada M, Kitayuguchi J, Lee IM, Hamano T, Imamura F, Inoue S, et al. Relationship between physical activity and chronic musculoskeletal pain among community-dwelling Japanese adults. Journal of Epidemiology. 2014;24:474-83.

11. Lunde LK, Koch M, Hanvold TN, Wærsted M, Veiersted KB. Low back pain and physical activity-a 6.5 year follow-up among young adults in their transition from school to working life. BMC Public Health. 2015;15:1115.

12. Landmark T, Romundstad PR, Borchgrevink PC, Kaasa S, Dale O. Longitudinal associations between exercise and pain in the general population-the HUNT pain study. PLoS One. 2013;8(6):e65279.

13. Leboeuf-Yde C. Body weight and low back pain. A systematic literature review of 56 journal articles reporting on 65 epidemiologic studies. Spine (Phila Pa 1976). 2000;25:226-37.

14. Heuch I, Hagen K, Heuch I, Nygaard O, Zwart JA. The impact of body mass index on the prevalence of low back pain: the HUNT study. Spine (Phila Pa 1976). 2010;35:764-8.

15. Janke EA, Collins A, Kozak AT. Overview of the relationship between pain and obesity: what do we know? Where do we go next? J Rehabil Res Dev. 2007:44:245.

16. Westerterp KR. Assessment of physical activity level in relation to obesity: current evidence and research issues. Med Sci Sports Exerc. 1999:31:S522-5.

17. Dyrstad SM, Hansen BH, Holme IM, Anderssen SA. Comparison of selfreported versus accelerometer-measured physical activity. Med Sci Sports Exerc. 2014:46:99-106

18. Ryan CG, Margaret Grant P, Dall PM, Gray H, Newton M, Granat MH. Individuals with chronic low back pain have a lower level, and an altered pattern, of physical activity compared with matched controls: an observational study. Aust J Physiother. 2009:55:53-8.

19. van Weering MG, Vollenbroek-Hutten MM, Tonis TM, Hermens HJ. Daily physical activities in chronic lower back pain patients assessed with accelerometry. Eur J Pain. 2009;13:649-54.

20. Verbunt JA, Westerterp KR, van der Heijden GJ, Seelen HA, Vlaeyen JW, Knottnerus JA. Physical activity in daily life in patients with chronic low back pain. Arch Phys Med Rehabil. 2001:82:726-30.

21. Raichlen DA, Foster AD, Seillier A, Giuffrida A, Gerdeman GL. Exerciseinduced endocannabinoid signaling is modulated by intensity. Eur J Appl Physiol. 2013;113:869-75.

22. Stagg NJ, Mata HP, Ibrahim MM, Henriksen EJ, Porreca F, Vanderah TW, et al. Regular exercise reverses sensory hypersensitivity in a rat neuropathic pain model: role of endogenous opioids. Anesthesiology. 2011;114:940-8

23. Tilg H, Moschen AR. Adipocytokines: mediators linking adipose tissue, inflammation and immunity. Nat Rev Immunol. 2006;6:772-83.

24. Murakami H, Kawakami R, Nakae S, Nakata Y, Ishikawa-Takata K, Tanaka S, et al. Accuracy of wearable devices for estimating Total energy expenditure: comparison with metabolic chamber and doubly labeled water method. JAMA Intern Med. 2016;176:702-3.

25. McClain JJ, Craig CL, Sisson SB, Tudor-Locke C. Comparison of Lifecorder EX and ActiGraph accelerometers under free-living conditions. Appl Physiol Nutr Metab. 2007;32:753-61.

26. Kumahara H, Schutz Y, Ayabe M, Yoshioka M, Yoshitake Y, Shindo M, et al. The use of uniaxial accelerometry for the assessment of physical-activityrelated energy expenditure: a validation study against whole-body indirect calorimetry. Br J Nutr. 2004;91:235-43.

27. Tudor-Locke C, Ainsworth BE, Thompson RW, Matthews CE. Comparison of pedometer and accelerometer measures of free-living physical activity. Med Sci Sports Exerc. 2002;34:2045-51.

28. Clemes SA, Griffiths PL. How many days of pedometer monitoring predict monthly ambulatory activity in adults? Med Sci Sports Exerc. 2008;40:1589-95.

29. Arnbak B, Jensen RK, Manniche C, Hendricks O, Kent P, Jurik AG, et al. Identification of subgroups of inflammatory and degenerative MRI findings in the spine and sacroiliac joints: a latent class analysis of 1037 patients with persistent low back pain. Arthritis Res Ther. 2016;18:237.

30. Slater H, Jordan JE, Chua J, Schutze R, Wark JD, Briggs AM. Young people's experiences of persistent musculoskeletal pain, needs, gaps and perceptions about the role of digital technologies to support their co-care: a qualitative study. BMJ Open. 2016;6:e014007. 
31. Wertli MM, Rasmussen-Barr E, Held U, Weiser S, Bachmann LM, Brunner F. Fear-avoidance beliefs-a moderator of treatment efficacy in patients with low back pain: a systematic review. Spine J. 2014;14:2658-78.

32. Vuori IM. Dose-response of physical activity and low back pain, osteoarthritis, and osteoporosis. Med Sci Sports Exerc. 2001;33:S551-86. discussion 609-610

33. Steffens D, Maher CG, Pereira LS, Stevens ML, Oliveira VC, Chapple M, et al. Prevention of low back pain: a systematic review and meta-analysis. JAMA Intern Med. 2016;176:199-208.

34. Fabris de Souza SA, Faintuch J, Valezi AC, Sant'Anna AF, Gama-Rodrigues JJ, de Batista Fonseca IC, et al. Postural changes in morbidly obese patients. Obes Surg. 2005;15:1013-6

35. Handschin C, Spiegelman BM. The role of exercise and PGClalpha in inflammation and chronic disease. Nature. 2008;454:463-9.

Submit your next manuscript to BioMed Central and we will help you at every step:

- We accept pre-submission inquiries

- Our selector tool helps you to find the most relevant journal

- We provide round the clock customer support

- Convenient online submission

- Thorough peer review

- Inclusion in PubMed and all major indexing services

- Maximum visibility for your research

Submit your manuscript at www.biomedcentral.com/submit
Biomed Central 